\title{
EVOLUÇÃO ESPACIAL DE FEIÇÕES EROSIVAS URBANAS NO NOROESTE DO PARANÁ: ESTUDO DE CASO DO MUNICÍPIO DE SANTA CRUZ DE MONTE CASTELO
}

\author{
Raquel Mendes Rodrigues ${ }^{(\mathrm{a})}$, Luciano Mattana Carollo da Luz ${ }^{(\mathrm{b})}$, Caroline Gonçalvez \\ Mangueira $^{(\mathrm{c})}$, Leonardo. José Cordeiro Santos ${ }^{(\mathrm{d})}$
}

\footnotetext{
(a) Geografia, Universidade Federal do Paraná, raquel.mr.rodrigues@gmail.com

(b) Geografia, Universidade Federal do Paraná, luciano_c.daluz@hotmail.com

(c) Geografia, Universidade Federal do Paraná, caroline.mangueira@hotmail.com

(d) Geografia, Universidade Federal do Paraná, santos.ufpr@gmail.com
}

\section{Eixo: GEOGRAFIA FÍSICA E DESASTRES NATURAIS}

\begin{abstract}
Resumo/
Os processos erosivos hídricos lineares causam um grande impacto ambiental e sua gênese está ligada a condicionantes naturais sendo potencializadas pela ação antrópica. Podem ocorrer tanto no meio rural quanto no meio urbano, sendo nesse último caso de grande significância, pois podem colocar em risco a vida da população e dos equipamentos urbanos. Nessas circunstâncias, a compreensão das suas causas e da sua interação com a área urbana pode auxiliar em futuros projetos urbanos e no combate e controle das feições erosivas. Um método possivel é o cadastramento dessas erosões, permitindo a análise do seu comportamento, podendo estimar sua evolução, sua dinâmica e seus processos, auxiliando no planejamento ambiental. A feição erosiva localizada próximo a área urbana do município de Santa Cruz de Monte Castelo, foi analisada em diferentes períodos por meio de imagens de satélites constatando-se o seu aumento em direção a área urbana.
\end{abstract}

Palavras chave: impacto ambiental; feição erosiva; planejamento.

\section{Introdução}

O noroeste do Estado do Paraná, historicamente sofre com processos de erosão linear, pois esta é uma região com alta suscetibilidade a perda de solo, devido principalmente as suas características geológica, geomorfológica e pedológica, além da maneira como foram instaladas as cidades nessa parcela do estado. Em relação a morfologia urbana, os arruamentos ficam situados ao longo das vertentes, seguindo o sentido montante-jusante, contribuindo para o início do processo erosivo.

As principais causas de surgimento das feições erosivas nas áreas urbanas está relacionada ao traçado inadequado do sistema viário juntamente com a compactação do solo e a deficiência do sistema de drenagem das águas pluviais e servidas, tanto nas formas de captação, como na dissipação (IWASA; FENDRICH, 1998). Inserido nesse contexto, identifica-se no município de Santa Cruz de Monte Castelo, uma feição erosiva próxima a sua área urbana (FIGURA 1). 


\section{OS DESAFIOS DA GEOGRAFIA FÍSICA NA FRONTEIRA DO CONHECIMENTO \\ Instituto de Geociências - Unicamp \\ Campinas - SP \\ 28 de Junho à 02 de Julho de 2017}

O objetivo do presente trabalho é realizar uma análise da evolução espacial da feição erosiva localizada em Santa Cruz de Monte Castelo, abordando a relação entre a área urbana e a extensão da erosão.

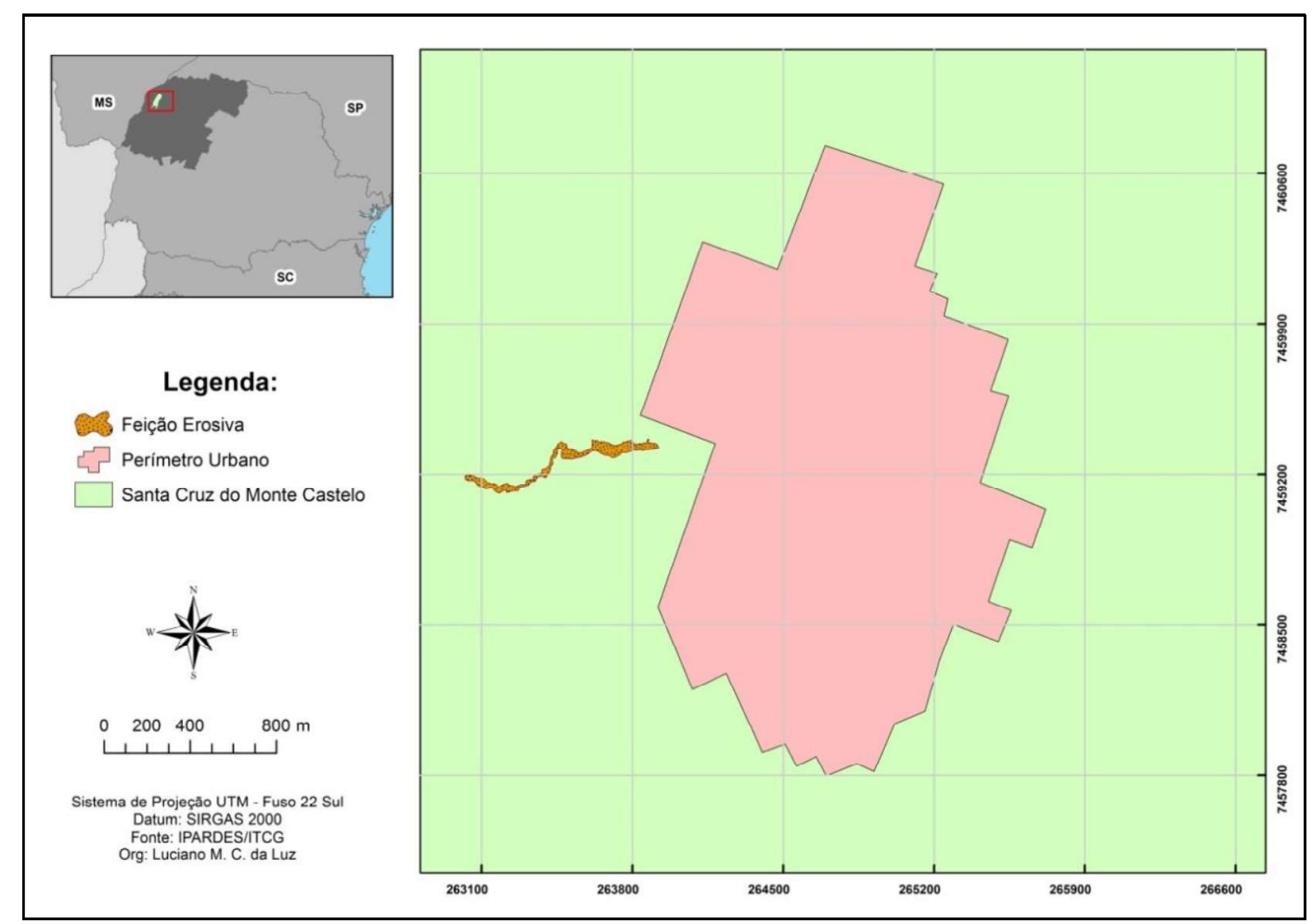

Figura 1 - Localização da área de estudo, feição erosiva. Fonte: Os autores, 2017.

\section{Material e Metódos}

O cadastramento de feições erosivas permite o conhecimento do comportamento destas. Deste modo, o mesmo porporciona dados fundamentais afim de garantir critérios mais abalizados de projetos de contenção.

A Ficha Cadastral de Erosões Urbanas foi elaborada pelo Laboratório de Biogeografia e Solos, da Universidade Federal do Paraná, conforme propostas já utilizadas por outros autores e instituições (CETAE e LARA, 2010; SOPCHAKI e SANTOS ,2012; IPT, 2012). A figura 2 apresenta um fluxograma simplificado do método de trabalho adotado para a identificação e cadastramento das erosões urbanas. 

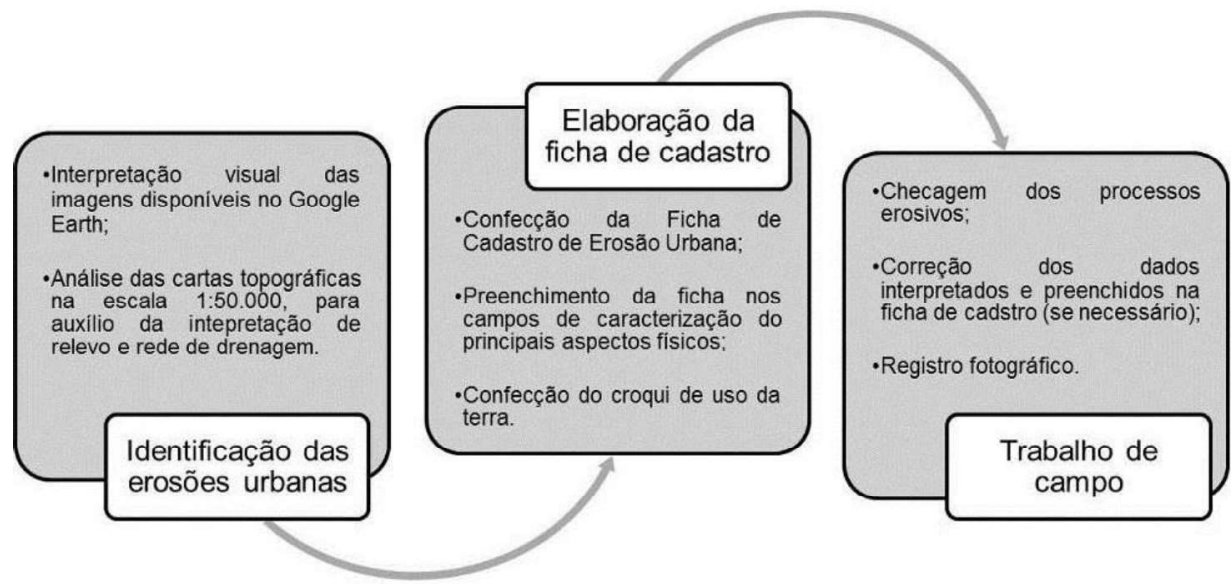

Figura 2 - Fluxograma do método para cadastramento das erosões urbanas. Fonte: Os autores, 2017.

No primeiro momento as feições erosivas foram identificadas por meio de interpretação de imagens disponibilizadas pelo banco de dados do Google Earth Pro, em uma análise temporal de 2005 à 2016. Os anos analisados foram 2005, 2013 e 2016, em virtude das imagens disponibilizadas somente nestas datas para o local de estudo. Esta verificação ocorreu dentro e próximo do limite urbano do município, sendo a identificação transcorrido por meio de interpretações buscando padrões visuais de indentificação de processos erosivos, como as cabeceiras de drenagem, cuja áreas à montante encontram-se urbanizadas.

Após essa etapa, com intuito de compreender a evolução da feição erosiva, realizou-se o georreferenciamento das imagens no ArcGIS 10.1 e posteriormente a delimitação dos polígonos das feições em diferentes datas. Em seguida, fez-se um cálculo estimado da erosão $\mathrm{em} \mathrm{m}^{2}$, verificando se houve o aumento de sua área.

A ficha de cadastro utilizada é composta de dados quantitativos e qualitativos, coletados tanto em laboratório quanto em campo. As informações reunidas, descrevem tanto as características da origem e da forma de ocorrência das feições erosivas, relacionando aos principais condicionantes de meio físico.

Por meio das imagens georreferenciadas, foi elaborado um croqui do uso da terra no entorno da feição, com o objetivo de detalhar a forma de ocupação nas proximidades destas feições e visualizar a disposição do arruamento.

Deste modo, é fundamental para a compreensão da interação da feição erosiva com a área urbana esse detalhamento juntamente com as observações de campo, possibilitando previsões de evolução e sugestão de medidas preventivas. 


\section{Resultados e Discussão}

Ao longo do período analisado de 2005 a 2016, percebe-se que a evolução da erosão acompanha o adensamento urbano e a pavimentação do arruamento. A evolução da feição erosiva, no período estudado, foi estimada $\mathrm{em} \mathrm{m}^{2}$ (FIGURA 3).

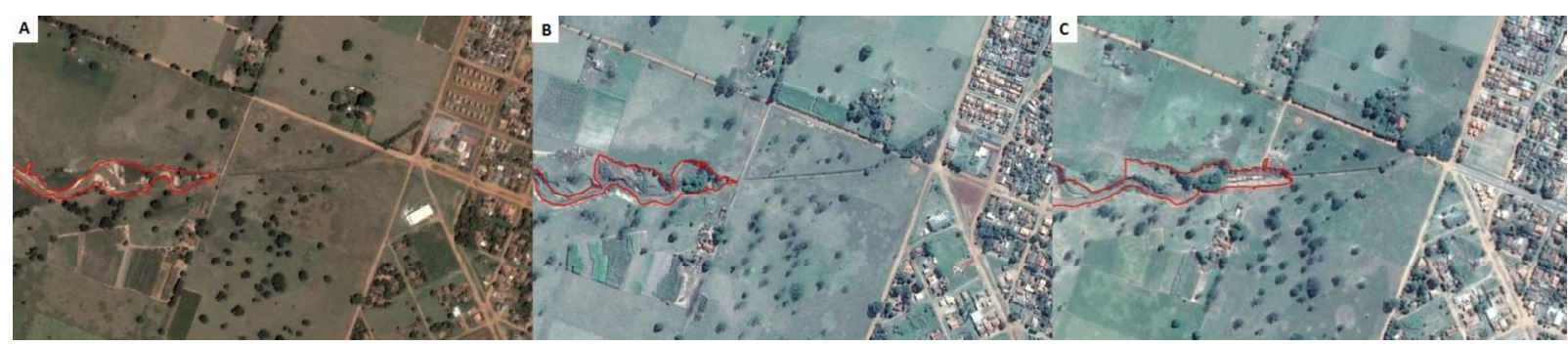

Figura 3 - Evolução da feição erosiva e sua estimativa em m². (A) Ano: 2005; área: 27.497 m². (B) Ano: 2013; área: $46.135 \mathrm{~m}^{2}$; crescimento: 19.656 m². (C) Ano: 2016; área: 50.880; crescimento: 4.745. Fonte: Os autores, 2016.

A feição erosiva tem seu comprimento estimado em 1.105 metros. Durante os anos analisados note-se que em 2005, a voçoroca já se encontrava em estado avançado. Em 2013, há um avanço da cabeceira da erosão, assim como o seu alargamento. Em 2016, há um aumento significativo da cabeceira da erosão e uma ramificação na sua margem esquerda. Em campo, realizado no mesmo ano, foram observados processos na sua cabeceira que determinam seu caráter ativo (FIGURA 4).

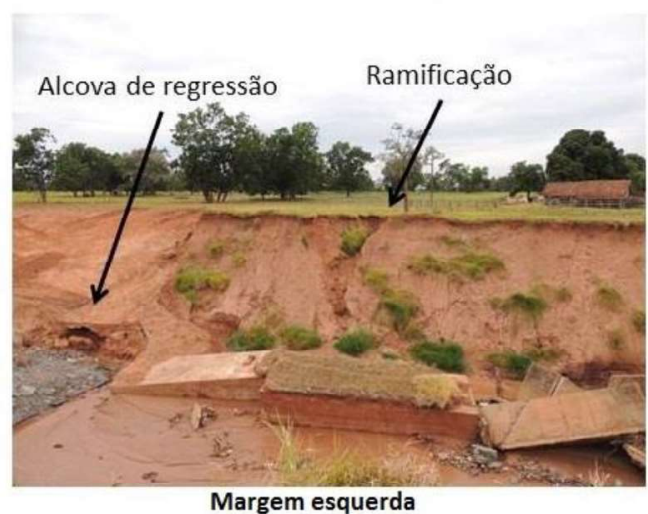

Margem esquerda

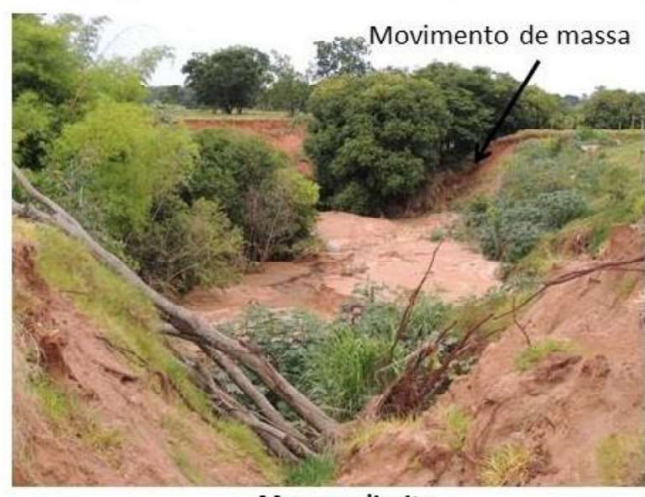

Margem direita

Figura 4 - Mecanismos erosivos encontrados na feição. Fonte: Os autores, 2016.

O solapamento da cabeceira dessa erosão, vista pela análise da sua evolução, causa o que chamamos de recuo remontante, que aumenta o comprimento das voçorocas, até que atinjam seu limite estável (OLIVEIRA, 1999). Por vezes, esse limite é encontrado já dentro da área urbana. Assim, a feição erosiva tende a crescer em direção a cidade, destruindo equipamentos urbanos e ocasionando risco de vida. 


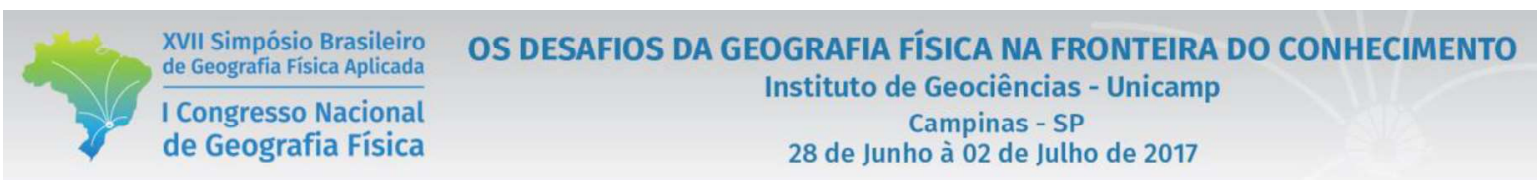

Na figura 5, é identificada a área de contribuição da feição, notando-se que a posição da cidade, no topo da vertente, juntamente com a impermibialização do arruamento e seu sentido montante-jusante, direciona o fluxo de escoamento superficial das águas pluviais. Esta combinação aumenta o fluxo e a energia desse escoamento acarretando o solapamento da cabeceira e contribui para o crescimento da feição erosiva em direção a cidade.

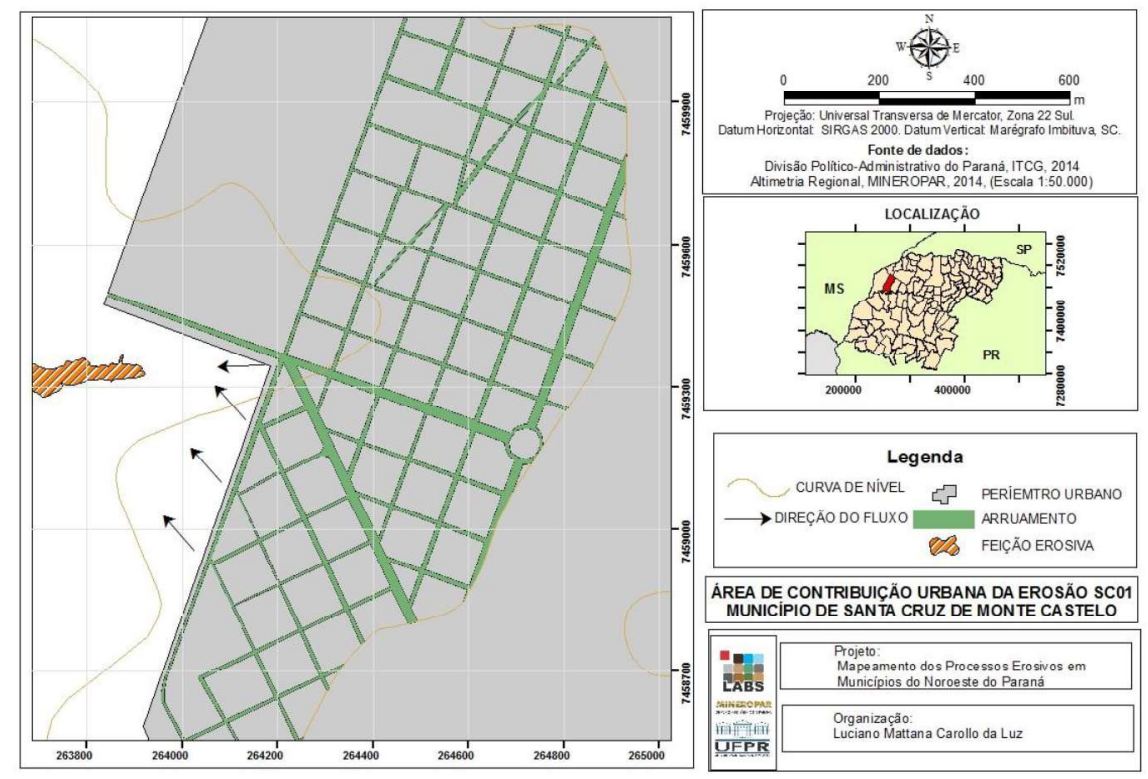

Figura 5 - Área de contribuição da feição periurbana de Santa Cruz de Monte Castelo. Fonte: Os autores, 2016.

\section{Considerações Finais}

A falta de análise integrada de um planejamento urbano, não levando em consideração as tendências de crescimento urbano e as caracteríscticas do meio físico, à luz das erosões urbanas, contribui para o seu surgimento e desenvolvimento. Foi constatado que a ação antrópica condiciona e potencializa o desenvolvimento remontante dessas feições através da interação entre a erosão e a área urbana.

\section{Bibliografia}

CENTRO DE TECNOLOGIAS AMBIENTAIS; LABORATÓRIO DE RISCOS AMBIENTAIS. Diagnóstico e proposição de diretrizes para a recuperação dos processos erosivos no município de Mirassol, SP. São Paulo: Secretaria de Desenvolvimento do Estado de São Paulo, 2010. Relatório técnico n.19414-301-57/208.

INSTITUTO DE PESQUISAS TECNOLÓGICAS DO ESTADO DE SÃO PAULO. Cadastramento de pontos de erosão e inundação no Estado de São Paulo. São Paulo: IPT, 2012. Relatório técnico n. 131.057-205. 


\section{OS DESAFIOS DA GEOGRAFIA FÍSICA NA FRONTEIRA DO CONHECIMENTO \\ Instituto de Geociências - Unicamp \\ Campinas - SP \\ 28 de Junho à 02 de Julho de 2017}

IWASA, O.Y; FENDRICH, R. Controle da Erosão Urbana. In: OLIVEIRA, A.M.S; BRITO, S.N.A de (Eds.). Geologia de engenharia. ABGE, Brasil, 1998, p.271-281.

JORGE, M.C.O. Geomorfologia Urbana: conceitos, metodologias e teorias. In: GUERRA, A.J.T. (Org). Geomorfologia Urbana. Rio de Janeiro: Bertrand Brasil, Brasil, 2011, p.117-146.

OLIVEIRA, M. A. T. Processos erosivos e preservação de áreas de risco de erosão por voçorocas. In: GUERRA, A. J; SIlva, A. S; BOTElHO, R. G. M. Erosão e Conservação dos Solos - Conceitos, Temas e Aplicações. Rio de Janeiro: Bertrand Brasil, 1999 , p. 56-99.

SOPCHAKI, C. H.; SANTOS, L. J. C. Metodologia de cadastro de erosões na Bacia do Rio do Meio, PinhaisPR. Geografia Ensino \& Pesquisa, vol. 16, n. 2, maio/ ago. 2012. 147-161p. 